\title{
SOCIAL SECURITY AND NATIONAL INSURANCE TRUST OF GHANA ANNUAL REPORTS: A READABILITY ANALYSIS
}

\section{WILLIAM KODOM GYASI AND LAWRENCE OWUSU-ANSAH}

(Received 31, January 2018; Revision Accepted 3, April 2018)

\begin{abstract}
The aim of annual reports is to give shareholders and other interested people information about a company's activities and financial performance. The Social Security and National Insurance Trust (SSNIT) of Ghana churns out annual reports on yearly basis. But some of the annual reports are likely to be more difficult to understand than others and may not be effective if the reader is unable to completely comprehend the contents. Yet, nothing is known about the readability of annual reports produced by SSNIT. Hence, this paper attempts to evaluate the readability of annual reports of SSNIT and establish the trend in readability, covering a period of years (from 2011 to 2015). SMOG readability index was used to compute readability scores and descriptive statistics and ANOVA were used to analyse the data. The results indicate that the annual reports of SSNIT were generally very difficult to comprehend. In addition, the study showed that the readability level of all annual reports was similar. The trend indicates a deterioration in readability of the annual reports over the five-year period. The researcher recommends that authors of the report use plain language to enhance ease in the understanding of the reports.
\end{abstract}

KEYWORDS: SSNIT, annual report, readability, Ghana, SMOG

\section{INTRODUCTION}

A corporate annual report is a formal communication document comprising quantitative information, narratives, photographs and graphs. It seeks to inform shareholders, creditors and others about a company's business history, its present financial status, and its expected direction. It is essentially a response to mandatory disclosure requirements of a national company or Business Act, and from regulatory agencies. It is also a medium for voluntary disclosures perceived to produce net corporate benefits.

An annual report is a credible database in that, first, it is complied with regulatory specifics; second, it reflects the integrity of management in communicating objectively and comprehensively; and finally, its content has undergone due audit process. No matter what the presentation style, organization of content, colour graphics, pictorial choice and overall length, the intelligence that must be communicated via this document is that which will enable diligent readers to perform or confirm ex ante risk-return assessment of the company. Principles of effective communication should be adhered to in disclosing this information.

One of the tenets of effective communication is that the messages received by readers are interpreted in the same way as that intended by the sender. An impediment to this correspondence occurs when narrative disclosures within annual reports are written at a comprehension level beyond the capacity of most of the target audience. Whether writing which is difficult to read is executed deliberately to mask some unfavourable aspect of corporate behaviour, or is performed unwittingly out of ignorance, the consequence is the same. At least

William Kodom Gyasi, Department of Communication Studies, University of Cape Coast, Cape Coast, Ghana.

Lawrence Owusu-Ansah, Department of English, University of Cape Coast, Cape Coast, Ghana. 
some investors are hindered in that they are unable to fully utilize information relevant to rational investment resource allocation decision making. Ineffective communication increases the likelihood of investor resource misallocation with actual and opportunity cost implications at both the individual and societal levels. This responsibility rests on those who prepare annual reports. They must ensure that the reports are written to meet the varying comprehension levels of the target audience.

Accounting research into the readability of annual reports was first published in 1952. Over the past 6 decades, annual report readability has been investigated in Australia (Lewis, Parker, Pound, \& Sutcliffe, 1986; Parker, 1982; Pound, 1981), Canada (Courtis, 1986), New Zealand (Healy, 1977), the UK (Jones, 1988; Smith and Taffler, 1992a, 1992b; Still, 1972) and the USA (Pashalian and Crissy, 1952; Schroeder and Gibson, 1990; Smith and Smith, 1971; Soper and Dolphin, 1964), and quite recently in Ghana (Gyasi, 2017). Findings have consistently revealed annual report prose passages to be at a reading ease level of difficult to very difficult, and beyond the fluent comprehension skills of about 90 per cent of the adult population and about 40 per cent of the investor population. In other words, those responsible for narrative sections of the annual report typically are writing corporate messages at a reading level beyond the comprehension levels of their target audience.

The purpose of this article is to extend the literature on this topic by examining the readability of Social Security and National Insurance Trust (SSNIT) of Ghana's annual reports from 2011-2015. The Social Security and National Insurance Trust (SSNIT) is a statutory public Trust charged under the National Pensions Act 2008 Act 766 with the administration of Ghana's Basic National Social Security Pension Scheme and to cater for the First Tier of the contributory three-tier scheme. The Trust is currently the largest non-bank financial institution in the country. Due to this critical role played by SSNIT, one would expect published accounts to be given close scrutiny by rational elements of the investment community and Ghanaian workers in general pursuing fundamental analysis. Even the speculative elements can be expected to use at least some annual reports to confirm their beliefs and gain additional knowledge about the companies in which they have an investment interest. A priori, one would therefore expect public companies to make a special effort in writing English prose which is easy to read. Thus, in this paper, we evaluated the following:

1. the readability of annual reports of Social Security and National Insurance Trust of Ghana.

2. the trend in readability of Social Security and National Insurance Trust annual reports over the years.

\section{REVIEW OF RELATED LITERATURE}

Readability, according to Stephens (2000) refers to the ease with which a document can be read and understood. Similarly, Gretchen Corp \& Jose (2000) state that readability, the "ease of reading words and sentences," is an attribute of clarity. Pikulski, (2013) gave a more explicit definition of readability that is in line with more recent research and theory by stating that readability is the level of ease or difficulty with which a text material can be understood by a particular reader who is reading that text for a specific purpose.

Readability indexes, which are mathematical formulas, were developed solely to assess the suitability of written text for intended readers. There are many readability formulas that are used to test the readability of texts in the English language. Some popular readability formulas include the Gunning Fog index, Smog index, Flesch Kinkaid Grade Level index, Flesch Reading Ease index, Fry Graph readability index and Spache readability index. All these formulas or indexes estimate the level of reading comprehension difficulty of a text by stating how many years of education a reader requires to comprehend a given text. According to Macdonald, McMillan, and Kerr (2010), these formulas often use word length, sentence length, and polysyllabic frequency in estimating the readability of a text. However, it should be noted that readability formulas cannot measure features like enjoyment or interest a reader derives in a particular reading (Stephens, 2000).

A number of studies have evaluated the readability of annual reports of corporate entities using various readability indexes. For example, in a study conducted in Malaysia, Courtis \& Hassan (2002), examined the reading ease between English and Chinese versions of 65 corporate annual reports in Hong Kong coupled with the English and Malay versions of 53 annual reports in Malaysia using Flesch and Yang Formulas for Hong Kong and Flesch and Yunus Formulas for Malaysia. Though the results were not conclusive, they provide a tentative impression that the indigenous language version is easier to 
read than the English-written versions. Findings also revealed that the English passages in Malaysian annual reports are easier to read than the English passages in Hong Kong annual report. Similarly, Bakar \& Ameer, (2011) also examined the readability of annual reports on Corporate Social Responsibility (CSR) for a sample of listed companies. Abubakar and Ameer (2011) employed readability formula and discovered that the extent of syntactic complexity influences the comprehension of CSR report. In essence, the higher the level of syntactic complexity in a given report of a company under review, the less comprehensible the report would be. They also examined the relationship between readability and companies' performance. Their findings revealed that the executives or directors of corporations with poor performance often compose their CSR report with low readability.

In this study, the Simple Measure of Gobbledygook (SMOG) readability index was used to calculate the readability of the annual reports. The SMOG formula is considered appropriate for secondary age readers that is, 4th grade to college level readers. The output which is interpreted in US school grade level indicates that the average student who can comprehend the text needs to acquire that grade level scale. For instance, average student in 7 th grade can understand the text having 7.4 score. This index was employed because it is recommended as a very reliable proxy to measuring readability (US Dept. of Health and Human Services, 2012). In addition, the SMOG readability index is noted to perform well for documents that are meant for relatively literate audience, such as financial disclosures.

\section{METHODOLOGY}

\section{Data Collection}

The annual SNNIT report is a compilation of reports from high ranking personnel and other supporting departments of the institute. Each year's financial statements are sandwiched with narratives by these personnel and departments. The sections within each year's report has changed over the years. Yet, two segments are consistently represented in each report: those of the chairman and the director general. Thus, the narratives of these two personnel were used to represent each year's report. The reports covered 2011 to 2015 since these were the reports which captured both segments as described.

For each report, texts under the two sections described above were selected for readability calculations. Hence, the readability of each subsection was calculated independently of the other, since each subsection required different writing approach.

\section{Data Analysis}

With the help of IBM Statistical Products and Services Solutions (SPSS) version 24.0, frequencies, percentages, means, and standard deviations were used to describe readability of the annual financial reports (objective 1).

A one-way analysis of variance, using bootstrapping technique, was performed for a sample of 1000 to ensure robust estimates of significance or $p$-value, standard errors and the confident intervals (McCormick \& Salcedo, 2017) to establish differences in readability of the reports over the years. To ensure robust confidence intervals, Bias corrected and accelerated $(\mathrm{BCa})$ intervals was used since it ensures adjusted intervals that are more accurate (McCormick \& Salcedo, 2017). Mersenne Twister Random Number Generator was set to replicate a sequence of random numbers. This helped to preserve the original state of the random number generator and restore that state after the analysis was completed. The Simple method was used since it helps to resample with replacement from the original dataset. No post-hoc analysis was conducted because the results of the ANOVA were statistically insignificant. In addition, means plot were plotted to establish the trend in readability of the reports that have occurred over the years under consideration.

\section{RESULTS AND DISCUSSION}

\section{Objective 1: Determining the readability of SSNIT annual report}

Table 1 presents descriptive statistics of the readability of annual financial reports of four Banks in Ghana, measured using the SMOG readability formula. Means (and standard deviations) were used to evaluate the readability of the annual reports as reported in the Table 1. 
Table 1: Descriptive Statistics

\begin{tabular}{llllll}
\hline Year & N & Min & Max & Mean & Std. Deviation \\
\hline 2015 & 4 & 10.70 & 15.80 & 13.07 & 2.09 \\
2014 & 5 & 10.30 & 15.80 & 13.38 & 2.29 \\
2013 & 4 & 6.80 & 12.90 & 10.95 & 2.79 \\
2012 & 4 & 6.00 & 10.60 & 9.12 & 2.11 \\
2011 & 3 & 8.80 & 13.40 & 11.26 & 2.31 \\
\hline
\end{tabular}

We see from Table 1 that for all the years, the reports used 'difficult' words and sentences when compared to reference SMOG scores (US Dept. of Health and Human Services, 2012). On the average, the most readable report was recorded in 2012, which required nine years of education to comprehend. It is noted that even for the most readable report, the readability was above recommended scores $\left(7^{\text {th }}\right.$ to $8^{\text {th }}$ grade) for public documents such as annual reports. This finding is consistent with the majority of earlier works (Gyasi, 2017; Lewis, Parker, Pound, \& Sutcliffe, 1986; Parker, 1982; Pound, 1981).

The purpose of annual reports is to provide information regarding a company's financial operations. This helps investors to make decision of whether or not they would invest in a company. In addition, for SSNIT, annual reports help inform the general public about how their investments are being managed which engenders confidence in the role of SSNIT. All these purposes are achieved when SSNIT communicates financial information effectively to clients. From the findings of this objective however, investors and regulators and the general public will have it a challenge to read the annual reports churned out by SSNIT since on the average, the words used are difficult to comprehend.

\section{Objective 2: Trends in readability of SSNIT annual reports over the years}

This objective was assessed using two analytical techniques, one complementing the other. First, one-way analysis of variance was conducted to establish differences (if any) in readability of the annual reports over the years (from 2011 to 2015). The result is presented in Table 2.

Table 2: ANOVA

\begin{tabular}{llllll}
\hline & Sum of Squares & df & Mean Square & F & Sig. \\
\hline Between Groups & 50.986 & 4 & 12.746 & 2.337 & .103 \\
Within Groups & 81.820 & 15 & 5.455 & & \\
Total & 132.806 & 19 & & & \\
\hline
\end{tabular}

From Table 2, it is concluded that no significant difference existed among the readability scores of annual reports over the years $\left(F_{(4,19)}=2.33 ; p=0.103\right)$.

Therefore, no posthoc analysis was conducted. The implication of this finding is that the annual reports have not changed (improved) significantly over the years. SSNIT have produced difficult to read reports for consecutive years. The pattern in readability has been demonstrated in means plot in Figure 1. 


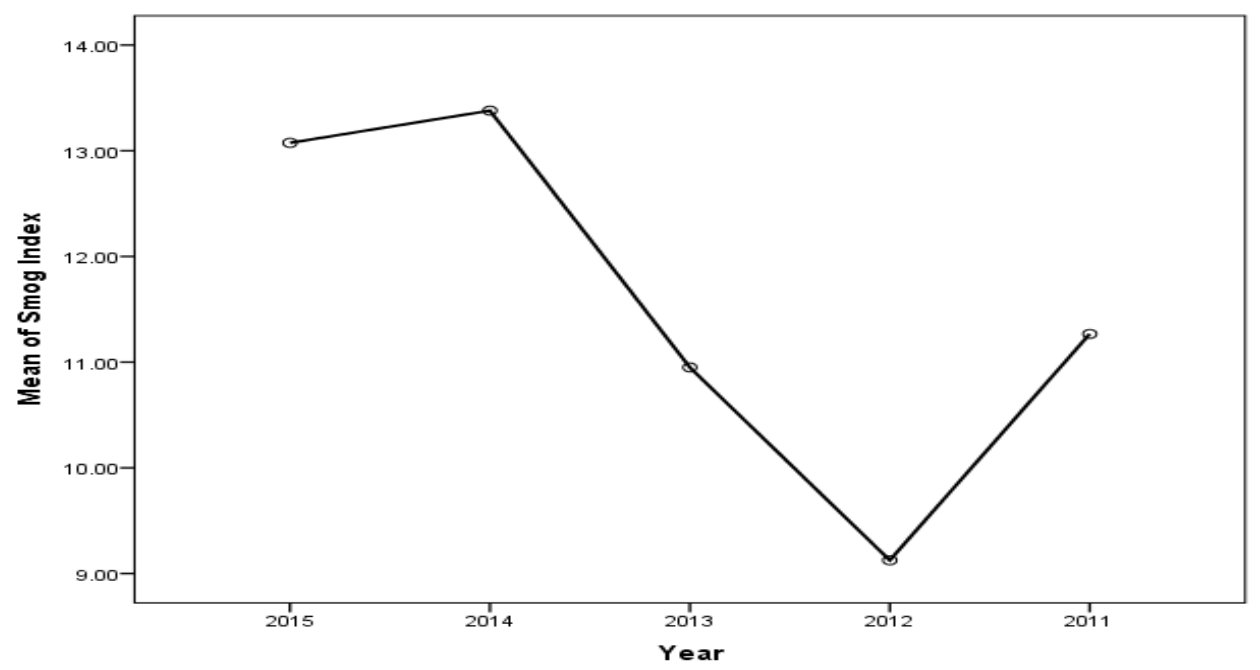

Figure 1: Means plot showing pattern in readability

It is observed from Figure 1 that the only apparent year which showed substantial improvement in readability (decrease in SMOG score) was between 2012. Thereafter, the readability of all subsequent years essentially degenerated, suggesting that no effort have been made to improve readability of the annual reports of SSNIT. This trend is consistent with the trend identified by Courtis \& Courtis (2006) who concluded that there has been no statistically significant improvement in annual report readability over the five- year period of their study of annual reports of corporate institutions in Hong Kong. This result could be a discouraging sign for those who are concerned with improvements in communication between SSNIT and their customers although it is not known whether the degeneration is the result of any conscious policy to hide the true nature of events.

\section{CONCLUSION}

The study examined the readability of annual reports of SSNIT. The first research objective sought to evaluate the readability of the annual reports of SSNIT when measured in terms of the SMOG readability index. The analysis revealed that the annual reports of SSNIT were generally difficult to comprehend. Amongst the reports covering five years, on the average, the most readable report required 9 years of education (2012) in order to comprehend. In contrast, the most difficult to read report (2014) required over 13 years of education to comprehend. This means that fluent comprehension of the messages contained within these passages is limited to only a few of the adult population of Ghana who have attained commensurate educational levels. This restricts effective communication and one means of facilitating rational resource decision making.

The second objective sought to establish a trend in readability of the annual reports over the five-year period. The study showed that the readability level of all annual reports was similar. The trend indicated a deterioration in the readability of the annual reports over the fiveyear period.

The first step in remedying this situation is for preparers of these reports to become aware of the problem. Until preparers acknowledge that written communications are not capable of being read with fluent comprehension by a significant proportion of their intended audience, the situation is not likely to improve. The second step is for preparers of this reports to actively improve readability levels by measuring their narrative disclosures and analyses to determine whether scores are predictive of readability. Any written document should become more readable through a conscious attempt to write more clearly, and through iteration with employees and investors via the submission of various drafts for comment. Improvements may be accomplished by first, writing shorter sentences; second, using shorter and simpler words in place of more complex and longer ones. Finally, attention to layout and format of information to enhance reader interest should be promoted 


\section{REFERENCES}

Bakar, A. S and Ameer, R., 2011. Readability of corporate social responsibility communication in Malaysia. Corporate Social Responsibility and Environmental Management, 18, (1): 50-60.

Courtis, J. K and Courtis, J. K., 2006. Readability of annual reports: Western versus Asian evidence. Accountability Journal, 8, (2), 4-17.

Courtis, J. K and Hassan, S., 2002. Reading ease of bilingual annual reports. The Journal of Business Communication, 394-413.

Courtis, J. K., 1986. An investigation into annual report readability and corporate riskreturn relationships. Accounting and Business Research, 16, (64): 285-294.

Gretchen, H., Corp, I and San Jose, C. A., 2000. Readability and computer documentation. ACM Journal of Computer Documentation, 24, (3), 122131.

Gyasi, W. K., 2017. Readability and institutional discourse: an analysis of University of Cape Coast vice-chancellors annual reports. African Journal of Applied Research, 3, (1): 72-81.

Healy, P., 1977. "Can you understand the footnotes to financial statements?", Accountants Journal, July, pp. 219-22.

Irwin, J. W and Davis, C. A., 1980. "Assessing readability: the checklist approach", Journal of Reading, November, 124-30.

Jones, M. J., 1988. "A longitudinal study of the readability of the chairman's narratives in the corporate reports of a UK company", Accounting and usiness Research, Autumn, 297-305.

Lewis, N. R., Parker, L. D., Pound G. D and Sutcliffe P., 1986. "Accounting report readability: the use of readability techniques", Accounting and Business Research, Summer, 199-213.
Macdonald, S., McMillan, T. M and Kerr, J., 2010. Readability of information leaflets given to attenders at hospital with a head injury. Emergency Medical Journal, 27(4), 279-282.

McCormick, K and Salcedo, J., 2017. Monte Carlo Simulation and IBM SPSS Bootstrapping. SPSSreg Statistics for Data Analysis and Visualization, 43-69.

Parker, L. D., 1982. "Corporate annual reporting: a mass communication perspective", Accounting and Business Research, Autumn, 279-86.

Pashalian, S and Crissy, W. J. E., 1952. "Corporate annual reports are difficult, dull reading, human interest value low", Journal of Accountancy, August, 215-9.

Pikulski, J. J., 2013. Readability. U.S.A: Houghton Mifflin Company.

Pound, G. D., 1981. "A note on audit report readability", Accounting and Finance, May, 45-55.

Schroeder, N and Gibson, C., 1990. "Readability of management's discussion and analysis", Accounting Horizons, December, 78-87.

Smith, J. E and Smith, N. P., 1971. "Readability: a measure of the performance of the communication function of financial reporting", The Accounting Review, July, $552-61$.

Smith, M and Taffler, R., 1992a. "Readability and understandability: different measures of the textual complexity of accounting narrative", Accounting, Auditing \& Accountability Journal, 5, (4): 84-98.

Smith, M and Taffler, R., 1992b. "The chairman's statement and corporate financial performance", Accounting and Finance, November, $75-90$

Soper, F. J and Dolphin, R., 1964. "Readability and corporate annual reports", The Accounting Review, April, 358-62. 
Stephens, C., 2000. All about readability. Delaware: The International Reading Association.

Still, M. D., 1972. "The readability of chairman's statements", Accounting and Business Research, Winter, 36-9.

US Dept. of Health and Human Services., 2012. Using readability formulas: a cautionary note. 